\title{
"Delas é o Reino dos Céus": Mídia Evangélica Infantil e o Supermercado Cultural Religioso no Brasil (Anos 1950 A 2000)
}

Karina Kosicki BELLOTTI ${ }^{\bullet}$

Resumo: Apresentamos uma História Cultural da mídia evangélica infantil produzida no Brasil entre os anos 1950 e 2000. Defendemos que o uso da mídia foi um importante fator para a constituição de uma cultura evangélica brasileira, voltada para o consumo individual e questões do cotidiano. A mídia para o público infantil fomentou intensa circulação de produtos culturais evangélicos, permitindo a construção de uma religiosidade transdenominacional. Analisamos produtos de mídia evangélica brasileira, como a revista adventista "Nosso Amiguinho", em circulação desde 1953, e o personagem "Smilinguido", campeão de vendas no mercado brasileiro desde os anos 1980. Focalizamos a recepção dos produtos Smilinguido para identificar os usos e os sentidos de sua cultura material e visual no cotidiano de crianças e jovens mulheres de diferentes filiações denominacionais do Brasil. Com o seu sucesso, um amplo mercado de bens cristãos abriu-se no Brasil durante os anos 1990 e 2000.

Palavras-chave: História Cultural; Mídia e Religião; Supermercado cultural.

\section{Introdução}

Este artigo analisa a mídia evangélica infantil produzida no Brasil entre as décadas de 1950 e 2000, sob a perspectiva da História Cultural. Defendemos a idéia de que o uso da mídia foi

\footnotetext{
- Pós-doutoranda - Departamento de História - Instituto de Filosofia e Ciências Humanas - UNICAMP - 13081-970 - Campinas - SP - Brasil. E-mail: karinakbellotti@yahoo.com
} 
um fator crucial para a constituição de uma cultura evangélica pós-moderna brasileira em um contexto de intensa competição religiosa. Nossa pesquisa, que resultou em uma tese de doutorado, mostra o poder da mídia infantil e de sua cultura material na difusão de uma cultura evangélica.

Denominamos evangélicos todos os grupos de origem protestante anglo-saxã que se instalaram no Brasil entre o início do século XIX (anglicanos, episcopais, presbiterianos, metodistas, batistas, congregacionalistas, adventistas) e as primeiras décadas do século XX (pentecostais em geral Assembléia de Deus, Congregação Cristã, Igreja do Evangelho Quadrangular, entre muitas outras), e seus desdobramentos nacionais ao longo de todo o século XX e início do século XXI. Em nosso trabalho, não trabalharemos com igrejas nem denominações específicas, mas sim com a produção midiática infantil feita por empresas evangélicas diversas ${ }^{1}$.

Nosso texto divide-se em quatro partes. Primeiramente, investiga-se o início do uso da mídia pelos evangélicos no Brasil e suas consequências para o campo religioso brasileiro, em seguida abordaremos a produção e o uso de mídia infantil evangélica dos anos 1950 até os anos 2000. A terceira parte refere-se a exemplos de recepção dos produtos da linha Smilinguido, segundo a análise de cartas de consumidores enviados à criadora do personagem, Márcia D'Haese, durante os anos 1990. Por fim, fecharemos com um panorama do supermercado cultural evangélico brasileiro, consequência direta do desenvolvimento desta mídia infantil a partir dos anos 1980.

A mídia infantil evangélica produzida no Brasil desde os anos 1950 em muitos casos não está ligada a nenhuma denominação específica. Seu consumo aumentou muito nos últimos vinte anos, enquanto muitos estudos acadêmicos enfatizaram pesquisas sobre determinadas instituições religiosas, em especial as igrejas pentecostais. Portanto, o tema da mídia infantil permitiu-nos analisar algo inexplorado, e encontrar conexões interessantes com a cultura material do cotidiano dos protestantes brasileiros. 
Por meio desses objetos enfatizamos as representações da infância, o ideal de cristão a ser formado e as relações entre esses ideais e a sociedade brasileira como um todo. Além disso, descobrimos que o investimento de muitas companhias evangélicas - e não somente de igrejas - nos valores familiares e na educação infantil criou uma área comercial comum em que diferentes tradições protestantes contribuem com produtos e mensagens similares. Essa situação constituiu um supermercado cultural evangélico no Brasil. Referimos-nos ao conceito de supermercado cultural estudado pelo antropólogo Gordon Matthews, como um mercado dirigido ao consumidor, no qual referências culturais circulam como mercadorias adquiridas e recombinadas por diversas pessoas, conforme suas preferências, desejos e formação cultural ${ }^{2}$.

Por meio do estudo de diversos produtos de mídia evangélica brasileira lançados entre 1940 e 2000, provamos duas hipóteses: primeiramente, a de que desde a década de 1950, o campo protestante brasileiro desenvolveu-se como uma cultura de massas, adotando o uso da mídia e de estratégias de propaganda para alcançar relevância na cultura popular. No Brasil, o uso da mídia por evangélicos foi introduzido por missionários americanos num campo religioso competitivo, no qual as táticas de inserção social contaram para o crescimento evangélico.

Por fim, provamos a hipótese de que esse período marca o início de um contato maior entre referências culturais evangélicas de diferentes orientações. $O$ avanço do fundamentalismo americano, assim como a ascensão pentecostal brasileira possibilitaram a circulação de produtos de mídia em um crescente mercado de consumo evangélico. A centralização da produção nos valores familiares fomentou uma cultura evangélica transdenominacional.

Portanto, diferentes tradições evangélicas foram usadas para construir múltiplas identidades evangélicas, em face aos desafios da pós-modernidade. Com a influência dessa mídia, houve a consolidação de uma cultura evangélica por meio da mistura de mensagens tradicionais em formatos 
contemporâneos, de acordo com a segmentação do mercado. Isso ocorreu durante o processo de constituição da cultura secular de entretenimento e informação, iniciada no Brasil em meados dos anos 1940 e 1950.

Contudo, esse mercado não vende uma simples mercadoria. Lidamos com a especificidade da religião e, por isso, consideramos não somente as estratégias de propaganda, mas também os discursos e os símbolos religiosos que sustentam a visão de seus produtores. Para seus consumidores e produtores, essa mídia carrega a missão de evangelizar e converter, seja por meio de livros, seja por meio de adesivos de carro.

Isso justifica a nossa escolha por uma abordagem cultural segundo o sociólogo Stuart Hall, que definiu a cultura como um mecanismo de constituição de sentidos e uma construção humana que perfaz modos de ser e viver, em constante transformação por meio da ação de indivíduos e instituições ${ }^{3}$.

Entendemos os protestantismos brasileiros no plural, como culturas que circulam e que são reapropriadas dentro e fora de instituições eclesiásticas. Por mais que haja um esforço de classificação do universo evangélico, a centralidade da cultura nos séculos XX e XXI dissolve e recombina elementos de diferentes tradições. Em nosso trabalho, a tradição é entendida não como um conjunto estável de práticas e crenças de igrejas, mas como um corpo doutrinário, ritualístico e histórico que é reconstruído e remodelado por meio da atividade diária de seus membros e fiéis, como uma cultura em transformação, em permanente negociação entre seus indivíduos:

A cultura é uma produção. Tem sua matéria-prima, seus recursos, seu 'trabalho produtivo'. Depende de um conhecimento da tradição enquanto 'o mesmo em mutação' e de um conjunto efetivo de genealogias. Mas o que esse desvio através de seus passados faz é nos capacitar, através da cultura, a nos produzir a nós mesmos de novo, como novos tipos de sujeitos. Portanto, não é uma questão do que as tradições fazem por nós, mas daquilo que nós fazemos das nossas tradições. Paradoxalmente, nossas identidades culturais, em qualquer forma acabada, estão à nossa 
frente. Estamos sempre em processo de formação cultural. A cultura não é uma questão de ontologia, de ser, mas de se tornar $(\ldots) .^{4}$

Por sua vez, essa cultura tem sido cada vez mais permeada pela mídia. Utilizaremos o conceito de cultura de mídia, desenvolvido pelo especialista em estudos de mídia Douglas Kellner, para lidar com produtos de mídia impressa, eletrônica e digital no seu conteúdo (mensagens) e nos seus formatos (meios), considerando sua produção, sua circulação e sua recepção ${ }^{5}$. A cultura evangélica contemporânea circula não somente por meio da mídia, mas também pelos circuitos do mercado consumidor de bens cristãos, que vem se constituindo no Brasil desde os anos 1980, e tem consolidado posição desde o final dos anos 1990. Por isso, ao lidarmos com produções midiáticas para o público infantil, também consideramos a cultura material e visual de massa que ajuda a divulgá-las em nosso país, tendo como base teórica os trabalhos dos historiadores norte-americanos David Morgan ${ }^{6}$ e Colleen McDannell ${ }^{7}$.

\section{Propagando a Fé - O Uso Evangélico da Mídia entre os anos 1940 e 1960}

O uso evangélico da mídia de massa no Brasil iniciou-se no final dos anos 1930 e no começo dos anos 1940, juntamente com a profissionalização dos meios seculares de comunicação ${ }^{8}$. Os evangélicos que usaram a mídia estabeleceram bases para a cultura evangélica, introduzindo novas idéias para os meios de evangelização e propaganda. Destacamos três pioneiros, cujas histórias mostram as potencialidades e as limitações encontradas pelos evangélicos no uso dos meios de comunicação.

O primeiro caso é o uso do rádio pelos Adventistas do Sétimo Dia, com o programa "A Voz da Profecia", em 1943. O segundo foi a produção de audiovisuais pelos evangélicos do 
Centro Audiovisual Evangélico (CAVE - 1952-1971 ${ }^{9}$ ), financiado pelo Conselho Nacional de Igreja de Cristo nos Estados Unidos ${ }^{10}$ (NCCCUSA). O terceiro foi o uso da mídia pela Cruzada Nacional de Evangelização, estabelecida no Brasil por missionários americanos pentecostais que fundaram a Igreja do Evangelho Quadrangular no Brasil, nos anos 1950.

Durante os anos 1950, a Igreja Católica começou a perder sua hegemonia no campo religioso brasileiro. Em 1891, a constituição republicana brasileira decretou a separação entre Estado e Igreja, mas até os anos 1950, a Igreja Católica continuou a exercer poder político e cultural. A partir de então, outras religiões passaram a competir por membros: as religiões da diáspora africana (candomblé e umbanda), o espiritismo, o protestantismo histórico e o pentecostalismo ${ }^{11}$. Ainda que no início tenha sido tímida, essa competição trouxe uma transformação irreversível para o campo religioso brasileiro, aliada à perda do poder político da Igreja Católica entre os anos 1950 e 1960.

O rádio foi adotado pelos evangélicos por ser o único meio de massa acessível em termos de custos e de retorno. Desde meados do século XIX, os primeiros missionários evangélicos usaram a imprensa e a distribuição de Bíblias e tratados como forma de comunicação, porém, sua inserção cultural foi limitada, pois a maioria da população brasileira era analfabeta. Assim, quando o rádio se popularizou em nosso país entre os anos 1930 e 1940, um novo investimento em propaganda foi feito.

O mais antigo registro de uso do rádio por evangélicos encontrado até hoje está no jornal presbiteriano "O Puritano", que em 10 de maio de 1938, convidava seus leitores a prestigiar em 15 de maio de 1938 a primeira irradiação do programa "A Voz Evangélica do Brasil", transmitido das 22h00 às $22 \mathrm{~h} 30$ aos domingos pela Rádio Transmissora Brasileira, PRE 2 do Rio de Janeiro: "Esse trabalho é fruto de colaboração de igrejas batistas, metodistas, episcopais, congregacionais, presbiterianas e presbiterianas independentes. Procuremos irmãos de todo Brasil ouvir o novo programa, interessar nele os seus amigos e orar por essa realização de alto significado" ${ }^{12}$. 
Posteriormente, houve a primeira transmissão do programa "A Voz da Profecia", pelos adventistas. Durante a Segunda Guerra Mundial, o sentimento de proximidade do Final dos Tempos inspirou os adventistas a proclamar o Evangelho pelos ares. A primeira mensagem foi um sermão de vinte minutos sobre as maravilhas da vida moderna ("Nosso Mundo de Maravilhas") - e os planos de Deus para acelerar o tempo à medida que o Julgamento Final se aproximava ${ }^{13}$.

Em 1952, outro esforço conjunto de protestantes históricos, financiados pela entidade NCCCUSA, deu início ao Centro Audiovisual Evangélico (CAVE), com o propósito de usar todos os meios de comunicação disponíveis para a evangelização e a educação. Inspirado pelos ideais do Evangelho Social, o CAVE produziu diversos tipos de materiais: programas de rádio, slides e diafilmes, flanelógrafos, livretos, um filme longa-metragem ("O Punhal", 1961) e um desenho animado ("Tonico e o Demônio", 1963). Seus administradores também compraram uma estação de rádio na cidade Jaguariaíva- $\mathrm{PR}$, a fim de competir com as estações de rádio católicas. Em correspondências da época, trocadas entre a direção do CAVE e seus financiadores americanos, havia inúmeras reclamações sobre supostas iniciativas de estações católicas para impedir a expansão evangélica. Porém, a iniciativa do CAVE foi ofuscada por problemas administrativos internos, que culminaram na falência da empresa em 1971.

No mesmo período, entre 1950 e 1970, os pentecostais da Cruzada Nacional de Evangelização usaram o rádio para promover tendas itinerantes, similares ao modelo americano de "camp meeting", em que centenas ou milhares de pessoas reuniam-se para ouvir pregações, ter uma experiência pessoal com Cristo e encontrar a cura para diversas enfermidades. No Brasil, a Cruzada usou o rádio dentro de uma estratégia empresarial de estabelecimento de igrejas: primeiramente, o missionário recebia uma pequena doação para firmar uma igreja em uma determinada cidade. Alugando horários na rádio local, o missionário anunciava sua tenda. Caso o número de pessoas atraídas para a tenda fosse suficiente para custear o horário da 
rádio, as despesas do pastor e o início de uma igreja, ele se estabelecia na cidade. Caso contrário, ele partia para outra cidade, utilizando a mesma prática ${ }^{14}$.

Por meio desses exemplos, observamos o surgimento de uma mentalidade competitiva entre evangélicos, aliada a um ímpeto missionário. Além disso, os programas de rádio enfatizavam mensagens cristãs moralistas e pragmáticas para o cotidiano, transmitidas em formatos populares para a época, tais como a conversação de cinco minutos, entrevistas, boletins, perguntas-e-respostas (quiz), e as radionovelas, o formato secular mais popular.

A idéia de que a mensagem cristã deveria atrair a atenção de qualquer ouvinte por meio do uso dos modernos recursos de comunicação era constantemente enfatizada em diversos documentos dirigidos a clérigos e leigos evangélicos. Entre as décadas de 1950 e 1960, os comunicadores evangélicos encararam uma tarefa difícil de convencer suas lideranças da relevância de se usar a mídia ${ }^{15}$. É interessante notar os argumentos levantados para defender a novidade totalmente entrelaçados a uma ideologia de marketing. Abaixo, um trecho bastante representativo dessa mentalidade, produzido por uma missionária americana e funcionária da RAVEMCCO, órgão que financiou o Centro Audiovisual Evangélico no Brasil (CAVE) nos seus anos iniciais:

Bilhões e bilhões de olhos e ouvidos, janelas para a mente do homem. Esse é o século que aprendeu a apelar para eles, milhares em um só tempo. Vendedores de sabão, promotores de shows, propagadores dos "ismos" estão erguendo pôsteres, expondo filmes, propagandas no rádio e na televisão. E onde está a Igreja Cristã? O que ela tem feito? Alguns homens disseram que o mundo é ganho pela ideologia cujos expositores souberem como melhor apresentá-la. Se isso é verdade, nós, cristãos, temos de acompanhar essa tendência ou desistir. $\mathrm{O}$ cristianismo oferece o que todos os homens perseguem - a Vida Abundante - e ainda assim ele tem ganhado relativamente poucos comunicadores. Talvez, a razão esteja no fato de que não tenhamos sido bem 
sucedidos em deixar suficientes homens verem claramente o que o Cristianismo oferece ${ }^{16}$.

Por meio dessa argumentação, observamos o que o sociólogo Leonildo Silveira Campos denominou de "marketing da fé", uma prática na qual os agentes religiosos procuram a melhor maneira de atender as pessoas em suas necessidades materiais e espirituais ${ }^{17}$. Aqueles que defendiam o uso da propaganda afirmavam o caráter neutro dos meios de comunicação, opondo-se aos evangélicos que desprezavam a mídia pelo seu conteúdo mundano. No século XXI, a neutralidade da mídia pode soar uma verdade óbvia para muitas pessoas, porém, em meados do século XX, a mídia começava a se tornar onipresente no cotidiano de muitos brasileiros nos centros urbanos, mas não sendo aceita por todos. Muitos evangélicos - em especial pentecostais (Congregação Cristã do Brasil e setores da Assembléia de Deus) - proibiram seus membros de ouvir rádio, assistir televisão e consumir jornais. Assim, a idéia da neutralidade da mídia era crucial para convencer pastores a usar os modernos recursos para a "glória de Deus" e, não, dos homens.

Ao oferecer os caminhos da felicidade e da alegria para todos no cotidiano presente, a mídia evangélica no seu início pretendeu dirigir-se à audiência brasileira, em um contexto de crescente urbanização, industrialização e secularização. O entretenimento de massa e de consumo era extremamente atraente para os sentidos, forçando católicos, evangélicos e líderes de outras religiões (espiritismo e candomblé, em especial) a encontrar novos e criativos modos para atingir tantos seus fiéis quanto os fiéis em potencial.

Como observado pelo sociólogo Paul Heelas, o século XX na sociedade ocidental é caracterizado pela pós-modernidade, cuja ênfase recai sobre a individualização, a cultura dirigida ao consumo individual, a desregulamentação das tradições e a desterritorialização ${ }^{18}$. $\mathrm{E}$, de fato, notamos uma forte tendência da mídia evangélica em se referir a questões práticas, bem-estar pessoal, situações e dilemas do cotidiano. Além dessa 
tendência, a mídia evangélica infantil que surge a partir dos anos 1950 também se conforma às tendências culturais gerais da sociedade brasileira no trato com a infância.

\section{Delas é o Reino dos Céus - Mídia Evangélica Infantil - de 1950 a 2000}

A mídia evangélica infantil seguiu os padrões e as mudanças da cultura pedagógica brasileira entre os anos 1950 e 2000. Da abordagem tradicional dos anos 1950 até a abertura ao construtivismo e a cultura de consumo, os produtos evangélicos para crianças foram cruciais para a formação de um supermercado cultural evangélico no Brasil ${ }^{19}$.

Nos anos 1950, juntamente com o uso de mídia de massa para fazer propaganda de cultos, serviços e igrejas, alguns evangélicos adotaram a mídia como uma forma de inserção e legitimação cultural, evitando mensagens denominacionais que pudessem desagradar católicos e simpatizantes. O exemplo da propaganda feita pela Igreja Adventista do Sétimo Dia é contundente, pelo seu uso do rádio e da colportagem, distribuindo revistas não-doutrinárias, tais como "Vida \& Saúde" e "Nosso Amiguinho".

Essa última, de circulação mensal desde 1953, adotou entre os anos 1950 e 1960, um discurso moralmente conservador, alinhado à tendência pedagógica tradicional daquele tempo, seguindo o caminho de publicações seculares infantis, como a revista "Tico-Tico"20 (a primeira revista infantil brasileira, publicada entre 1905 e 1955). "Nosso Amiguinho" representava a criança como tábua-rasa, que deveria obedecer aos pais e às autoridades a fim de ser um bom cristão brasileiro. Havia uma ênfase na religiosidade pragmática, orientada para a moral, a família e os valores patrióticos, ao invés de uma retórica calcada na doutrinação intensiva. Ao mesmo tempo em que essa revista procurou se inserir na cultura brasileira, procurou se diferenciar de outras mídias infantis porque oferecia uma alternativa "saudável" de educação e entretenimento, altamente visual. 
Essa alternativa se opunha ao tremendo sucesso de revistas em quadrinhos infanto-juvenis que circulavam no Brasil entre os anos 1940 e 1960. Os quadrinhos começaram a ser combatidos por uma intensiva campanha de padres e educadores brasileiros ${ }^{21}$. Na revista adventista, havia uma forte estigmatização do "mau" lazer, isto é, quadrinhos, programas de televisão, filmes de violência e aventura. Um terço de suas páginas eram dedicadas a palavras-cruzadas, charadas, labirintos, bonecas de papel e experimentos científicos simples. Isto é, educação e lazer saudáveis, em oposição ao lazer "hedonístico", tais como os quadrinhos seculares, que eram vistos como perigosa influência para o caráter:

Crianças, tenham cuidado com o que vocês lêem. Há muitos livros e revistas que não são bons. Há revistas que são fonte de emoções e o que nelas está escrito pode levar meninos e meninas à prática de atos criminosos. As revistas contendo histórias de crime e novelas policiais publicadas hoje em grande escala, não devem ser procuradas por vocês. Impressionados com histórias de quadrinhos vocês aprendem coisas de personagens sinistras, ficando o espírito povoado de cenas de crimes ${ }^{22}$.

Hoje em dia as crianças estão se tornando muito desobedientes. É provável que tenham sido influenciadas por algumas revistas de quadrinhos, alguns filmes seriados exibidos no aparelho de televisão, etc, embora aconselhadas e advertidas contra o perigo e as conseqüências de seu proceder ${ }^{23}$.

Em edição de agosto de 1966, "Nosso Amiguinho" trouxe o curioso "Juramento da Escola Paulista", fornecido pelo Serviço de Divulgação da Secretaria de Segurança Pública e Polícia Preventiva do Estado de São Paulo, endossando essa perspectiva:

Juro respeitar o meu professor, meus pais - não ler as más histórias em quadrinhos - ter cuidado ao atravessar a rua respeitar o guarda que é amigo da criança - não ofender com palavras ou gestos o meu colega - amar o Brasil. Assim prometo pelo bem da criança brasileira. ${ }^{24}$ 
Contudo, até mesmo "Nosso Amiguinho" passou a incorporar a idéia de usar personagens de quadrinhos, simbolizados pelo menino Noguinho, seu cãozinho Azeitona e seus amiguinhos, acrescentados aos poucos nas páginas da revista a partir dos anos 1970. Os personagens representavam a diversidade étnica do Brasil, com personagens descendentes de diferentes povos: Sabino (oriental-japonês), Gina (indígena), Quico (alemão), Cazuza (africano), Luiza (italiana) e Noguinho (italiano).

No mesmo período, uma significativa mudança cultural ocorreu em nosso país, com o investimento da ditadura militar (1964-1985) fez em prol da integração nacional, enfatizando as telecomunicações e rede de estradas. Em termos de cultura infanto-juvenil, desde os anos 1970 houve um aumento no mercado consumidor de produtos infantis. Em 1966 o Dia da Criança foi criado pela indústria de brinquedos Estrela para promover suas vendas.

Além disso, houve uma crescente adoção de novas tendências construtivistas por parte do sistema educacional ${ }^{25}$ (primeiramente na rede privada, e posteriormente, pela rede pública). Esses fatores trouxeram uma nova representação para a infância, em que a criança é considerada uma consumidora e uma cidadã (esta última, em especial, após o final da ditadura).

Essa nova fase é bem representada na criação do personagem Smilinguido, uma pequena formiga que se tornou o maior sucesso de vendas no mercado evangélico infantil. Seus criadores foram a artista plástica Márcia Macedo D'Haese e o roteirista Carlos Tadeu Grzybowski ${ }^{26}$, que pertenciam a um grupo de mocidade da Igreja do Cristianismo Decidido de Curitiba-PR e pretendiam produzir um filme animado evangélico com uma mensagem de otimismo para as crianças, a fim de oferecer um uso alternativo da mídia, independentemente da denominação de sua audiência.

Contudo, devido à grave crise financeira pela qual passava o Brasil nos anos 1980, a estratégia para fazer o personagem conhecido foi a divulgação de tirinhas publicadas em jornais locais, além de slides com audiocassetes, cartões e marca- 
páginas - este, o produto mais rendoso da formiguinha desde então. $O$ personagem ajudou a abrir um novo mercado consumidor de bens cristãos para crianças e adolescentes, à medida que o investimento em mídia para a família e para as crianças feito por outras companhias evangélicas fez aumentar a circulação de bens culturais para os protestantes.

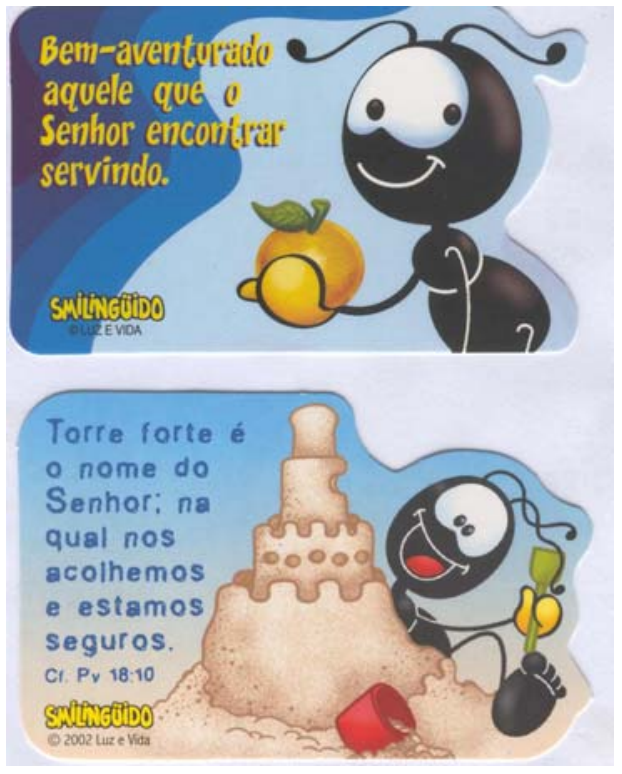

FIGURAS 1 e 2) Dois exemplares de produtos do personagem Smilinguido - dois cartões "passe adiante", com tamanho aproximado de $9 \mathrm{~cm} \times 5,5 \mathrm{~cm}$ (vendidos em 2005). Ilustradas com cores vivas, as imagens estão obrigatoriamente atreladas a um texto escrito (mensagem cristã ou adaptação de texto bíblico), visando orientar a leitura e a recepção do consumidor. As imagens são feitas para se harmonizar ao texto bíblico, trazendo referências aos elementos centrais da mensagem - como o oferecimento de uma fruta para se referir à idéia de serviço, ou o castelo de areia, referindo-se à "torre forte".

Fonte: arquivo pessoal da autora. 
Por um lado, o sucesso de Smilinguido estimulou a competição e a padronização, o que fez abrir ainda mais o mercado consumidor evangélico. Por outro lado, seus produtos foram apropriados de diversas maneiras por diferentes grupos. Tal como ocorreu nos Estados Unidos com a pintura "A Cabeça de Cristo" (Head of Christ), do artista americano Warner Sallman, estudado por David Morgan ${ }^{27}$, Smilinguido tornou-se um fenômeno cristão: ele é católico para os católicos, e protestante para os protestantes, atrativo até para aqueles que não possuem uma orientação religiosa específica.

Márcia D'Haese definiu a missão do personagem como a transmissão de mensagens cristãs de amor e restauração por meio de algo frágil e pequeno, simbolizado pela formiguinha. Além disso, observamos que os produtos do personagem trazem uma mensagem de simplicidade, solidariedade, cooperação, amizade e otimismo.

Sem dúvida, o produto mais popular é o marca-página ou marcador de Bíblia, criado como uma lembrança para ser dada ao final a exibição de slide com histórias do personagem, no início dos anos 1980. Era uma forma de fixar a mensagem bíblica central da história, condensada em um desenho e um curto versículo bíblico. O sucesso do marca-página levou a outros produtos licenciados, tais como camisetas, chaveiros, bótons, quebra-cabeças, adesivos, cartões, produtos escolares, dentre muitos outros. Atualmente, o personagem está presente em cerca de 800 produtos licenciados ${ }^{28}$.

A abundância e a variedade desses produtos podem sugerir que o personagem visa satisfazer mais a um mercado do que a um propósito evangelístico. Porém, para muitos comerciantes evangélicos, o próprio mercado é considerado algo a ser usado por Deus para seus propósitos. A perspectiva histórica de nossa pesquisa focalizou no sentido que esses produtos obtiveram no mercado da cultura evangélica. Tal como destacou a historiadora americana Colleen McDannell:

Adorar enquanto se realiza uma atividade mundana - andar de skate, esfregar a banheira, tirar o lixo de casa - é risível. Para um 
evangélico, contudo, a presença de Deus pode ser sentida em qualquer situação. Se você está do lado de fora de um sistema de crença, o mundano parece empobrecer a fé; se você está dentro do sistema, a fé glorifica o mundano. ${ }^{29}$

Definitivamente, esses produtos "mundanos" foram incorporados pela tradição evangélica de sacerdócio universal dos crentes, no qual qualquer convertido deve testemunhar o poder transformador de Cristo. Os fãs de Smilinguido distribuem, copiam, redesenham, fixam painéis e cartazes, pequenos adesivos, marca-páginas; enviam cartões e pequenas lembranças com mensagens curtas decoradas com a formiguinha sorridente. Devido à simplicidade do traço, o personagem pode ser facilmente reproduzido. Por isso, consideramos esses produtos importantes elementos para a mídia evangélica brasileira desde o início dos anos 1980, à medida que foram adotados como parte do seu cotidiano por audiências católicas e protestantes.

Essa popularidade trouxe à Márcia D'Haese a preocupação com os tipos de recepção de seu personagem. Ainda que nenhum produtor de mídia possa exercer pleno controle sobre sua audiência, D'Haese criou códigos de textualidade para serem usados em qualquer produto Smilinguido: a associação entre o desenho e a mensagem escrita. Esse recurso é um expediente muito comum no universo protestante desde a Reforma (1517), tal como afirmou o historiador David Morgan, "a textualidade refere-se ao envio da mensagem e à correta decodificação da mensagem. Acuidade, credibilidade e autoridade estão entre as preocupações culturais da textualidade" ${ }^{30}$. Assim, a imagem deve ser subordinada à mensagem escrita, a fim de comunicar o sentido "correto". Contudo, quando analisamos os usos do personagem a partir das mensagens enviadas pelos fãs de Smilinguido em cartas a Márcia D'Haese, diferentes sentidos emergiram, alguns deles inesperados pela artista. 


\section{Recepção e Construção de Religiosidades - 0 Caso de Smilinguido (Anos 1990)}

Analisamos cerca de 75 cartas enviadas entre 1991 e 1997 para Márcia D'Haese, de diferentes partes do Brasil e de diferentes filiações cristãs. Destas, 70 cartas foram enviadas por evangélicos, na sua maioria por jovens mulheres. Apenas cinco cartas analisadas vieram de católicas. Porém, esta foi somente uma amostragem de grande acervo de correspondências que a artista recebeu durante seus 17 anos de produção de Smilinguido (1980-1997) ${ }^{31}$.

Por exemplo, algumas pessoas sugeriram parcerias, enviando-lhe desenhos da formiga com mensagens personalizadas. Uma irmandade católica, "Irmãs Filhas do Divino Zelo", pediu-lhe permissão para usar o personagem em marca-páginas com o logotipo de sua missão ("Roga-te"), em carta de 19 de junho de 1996.

Em 15 de janeiro de 1993, uma pessoa do Ministério Fonte da Vida de Ipatinga-MG escreve a D'Haese solicitando um personagem surdo para ajudar no trabalho com surdos-mudos. Porém, a mesma remetente dispensou o personagem sem grandes explicações. Mas interessa-nos observar o papel de legitimação social que a mídia tem desempenhado ao dar visibilidade a sujeitos comumente negligenciados pela grande mídia.

Uma fã católica pediu a Márcia D'Haese o catálogo de seus produtos para vender em sua loja de aviamentos: "Gostaria de vender estas maravilhas em nossa loja que é de aviamentos para costureiras mas como dou muita 'catequese no balcão' também acho que seria a única coisa diferente que eu gostaria de oferecer aos meus clientes" (C.M. ${ }^{32}$, 1994). Smilinguido aparece como um meio de evangelização para as mulheres que não possuem muito espaço institucional dentro de suas igrejas. E nos anos 1980 e 1990, tornou-se também uma fonte de renda em um contexto de instabilidade financeira.

Nesse sentido, é interessante o exemplo de uma empresa de artigos de festa infantil que durante um ano usou o 
personagem para promover festas sem a permissão dos criadores da formiga. Para esses comerciantes evangélicos, a principal permissão veio de Deus:

(...) O Senhor falou um dia (mais ou menos final de junho de 1993) que era para fazermos festa, mas com uma diferença incrível, com temas bíblicos. Hoje nossa proposta é o evangelismo pleno e total em um ângulo que o Senhor não havia mexido e o melhor de tudo é que Ele escolheu a nós: S. e W. ${ }^{33}$ para fazer isso! E irmãos, que creiam que quando colocamos o Senhor em primeiro lugar em tudo Ele faz maravilhas, prova é o sucesso do Smilingüido. ${ }^{34}$

Algo semelhante, porém sem fins lucrativos, foi feito por um artista de rua, que pintou diversos muros da cidade de Jequié-BA, declarando o senhorio de Jesus sobre a cidade. Vale notar que várias escolas infantis passaram a solicitar a Márcia D'Haese a permissão para pintar o personagem nos seus muros. Desde então, qualquer escola pode usar o personagem desde que não faça propaganda da empresa com a formiga.

Outros fãs escrevem para parabenizar Márcia D'Haese pelo sucesso, e aproveitam para comunicar os benefícios trazidos pelo personagem e a afeição que sentem pela sua mensagem: "Amo a sua personagem, o Smilingüido, pela benção que ele é na minha vida, e também porque com ele se tornou mais fácil evangelizar. As pessoas não têm barreiras nem defesas quando são surpreendidas pelas suas mensagens", declarou A.P., adolescente de Ouro Fino-MG, em 18 de novembro de 1993. Outra moça, L.S., de 22 anos, residente em São José dos Campos - SP, relata em 14 de outubro de 1994 como o personagem a ajudou com seu trabalho de aconselhamento de jovens:

Você sabe que o meu desejo sempre foi servir ao Senhor como conselheira na área de cura interior com adolescentes, e eu sempre gostei de comprar figurinhas suas com mensagens que fala sobre o amor de nosso Deus. E já virou costume eu distribuir essas mensagens, eu amo escrever cartas falando aos amigos sobre o imenso amor de Deus, e outro dia uma colega de Faculdade, que é o local onde eu gosto de fazer amigos para falar 
do Senhor, me disse que realmente eu estava sendo usada por Deus através de suas figurinhas para evangelizar, eu até chorei de alegria, pois tudo o que peço ao Senhor é que me dê humildade e me use em sua obra.

Contudo, devemos ter em mente que esse personagem cristão circula em uma sociedade perpassada pela cultura do entretenimento, na qual imagens tornam-se ícones para a satisfação pessoal. Smilinguido não esteve impermeável ao estrelato: ele também se tornou um ícone para parte de seus admiradores - e para pirateadores, que reproduziram e venderam diferentes produtos com e sem a mensagem cristã.

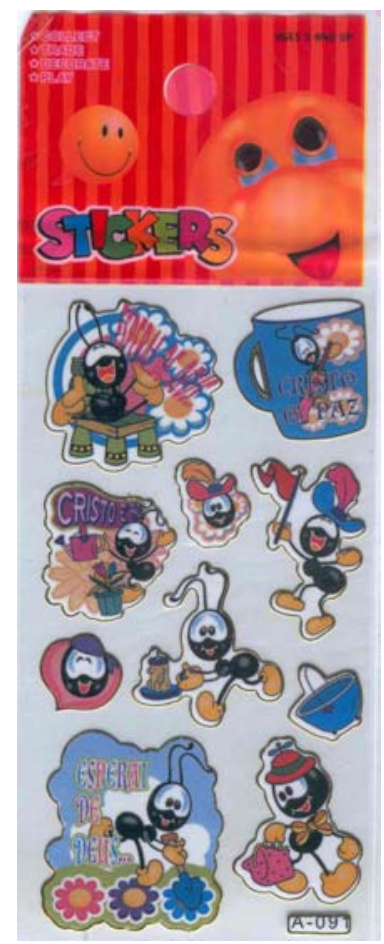

FIGURA 3) Exemplo de produto pirateado, no qual Smilingüido não aparece em todas as figuras atrelado a uma mensagem cristã. A pirataria desse personagem nos mostra como ele tem sido apropriado por várias pessoas como um ícone. Diferentemente do que desejava a criadora, Márcia D'Haese, a recepção do personagem não obedeceu totalmente à sua missão evangelizadora, por conta do contexto em que a formiguinha circula - no contexto da cultura popular de massa.

Fonte: acervo pessoal da pesquisadora; material comprado em 2005.

HISTÓRIA, São Paulo, 28 (1): 2009 
Os produtos de Smilinguido são voltados para a vida cotidiana, na qual as pessoas são desafiadas a lidar com problemas, frustrações e situações inesperadas. Por isso, encontramos muitos cartões e marca-páginas com mensagens otimistas, reconfortantes e encorajadoras para diversas ocasiões. Esses e outros objetos tornaram-se lembretes das crenças dessas pessoas, que são passadas para outras tantas, crentes e não crentes.

Os evangélicos usam objetos e imagens para penetrar as mais variadas fendas do cotidiano fragmentado, repetitivo e dessacralizado, que está aberto à espontaneidade e à improvisação. Camisetas, adesivos de carro, chaveiros, presentes são instrumentos para protestantes missionários, em especial mulheres, que agarram cada oportunidade para testemunhar o amor de Deus, mesmo quando confrontados com a rejeição das pessoas às suas mensagens ${ }^{35}$.

As imagens dessa cultura material representada por Smilinguido ajudaram a construir uma cultura evangélica altamente visual no Brasil. Isso se diferencia da prática adotada por muitos protestantes brasileiros de controle e quase banimento de imagens, a fim de distinguir sua cultura da cultura católica. Isso não significa afirmar que os protestantes brasileiros passaram a adorar imagens, mas sim que os produtores de mídia evangélica estão extremamente afinados com as demandas do mercado cristão e com os mais recentes lançamentos do mercado evangélico americano. Assim, eles oferecem bens e mercadorias para um estilo de vida cristão moderno. Como afirmou McDannell: "Não podemos mais aceitar que a 'aparência' da religião seja inconseqüente em relação à 'experiência' da religião. Os elementos sensuais do Cristianismo não são meramente decorações que mascaram crenças sérias; é por meio do mundo visível que o mundo invisível torna-se conhecido e sentido" ${ }^{36}$. 


\section{Supermercado Cultural Evangélico}

O sucesso e a profissionalização do mercado voltado para a família trouxeram a competição e a padronização. Além do crescimento pentecostal, que se utilizou de diversas estratégias de propaganda - da comunicação interpessoal de comunidades independentes ao uso sistemático da mídia por igrejas neopentecostais -, a inserção fundamentalista americana no Brasil contribuiu para a formação de um mercado de música gospel ao trazer movimentos de louvor e de mocidade com apelo interdenominacional ${ }^{37}$. Juntamente com esses dois fatores, a mídia infantil também foi crucial para a formação de um supermercado cultural evangélico.

À semelhança do supermercado real, no supermercado cultural, diversos produtos semelhantes disputam pela atenção dos consumidores, utilizando-se da propaganda. Porém, nesse supermercado virtual, nem sempre é necessário possuir dinheiro para adquirir seus bens culturais. A tônica desse conceito é que os indivíduos escolhem seus referenciais culturais e os combinam de diversas maneiras.

Aplicando esse exemplo para a religião, o supermercado cultural evangélico promove diversos tipos de religiosidade, disponíveis em diferentes espaços, dentro e fora das igrejas. $\mathrm{O}$ fato de a mídia evangélica infantil ter suprido uma demanda reprimida por bens cristãos de consumo, estimulou o investimento de igrejas, ministérios independentes e empresas evangélicas em produtos voltados para a criança e para a família, apostando cada vez mais nos consumidores-fiéis e, não tanto, nos fiéis desta ou daquela denominação.

Esse contexto explica a realização anual na cidade de São Paulo da Expo Cristã, uma grande feira de produtos evangélicos que ocorre desde 2002, reunindo expositores de diferentes orientações evangélicas, vendendo produtos os mais variados. Produtos tradicionais, como Bíblias e livros de aconselhamento dividem espaço com vestuário (camisetas - "Church Wear", becas e fantasias para peças de teatro), material escolar (em que prevalecem os personagens infantis), presentes, jóias, bijuterias, 
decoração doméstica, DVDs e CDs de bandas gospel e de diversos estilos musicais, games, jogos de tabuleiro, bonecos para meninos e meninas, bonecos de pelúcia, alimentos, entre outros.

No que se referem à mídia infantil, dois exemplos de competição que se seguiram ao sucesso de Smilinguido são os personagens da turma de Mig e $\mathrm{Meg}^{38}$, e a nova edição de "Nosso Amiguinho"39. Os primeiros foram criados por Márcia D'Haese em 1997, após a sua saída da editora Luz \& Vida ${ }^{40}$, que até hoje publica Smilinguido. Já a turma do Noguinho, de "Nosso Amiguinho", estampa outros produtos além da sua própria revista, tais como DVDs com histórias infantis, músicas, Bíblias, jogos, camisetas e material educativo. Esses produtos reafirmam as tendências pedagógicas e de lazer para a mídia infantil na sociedade secular.

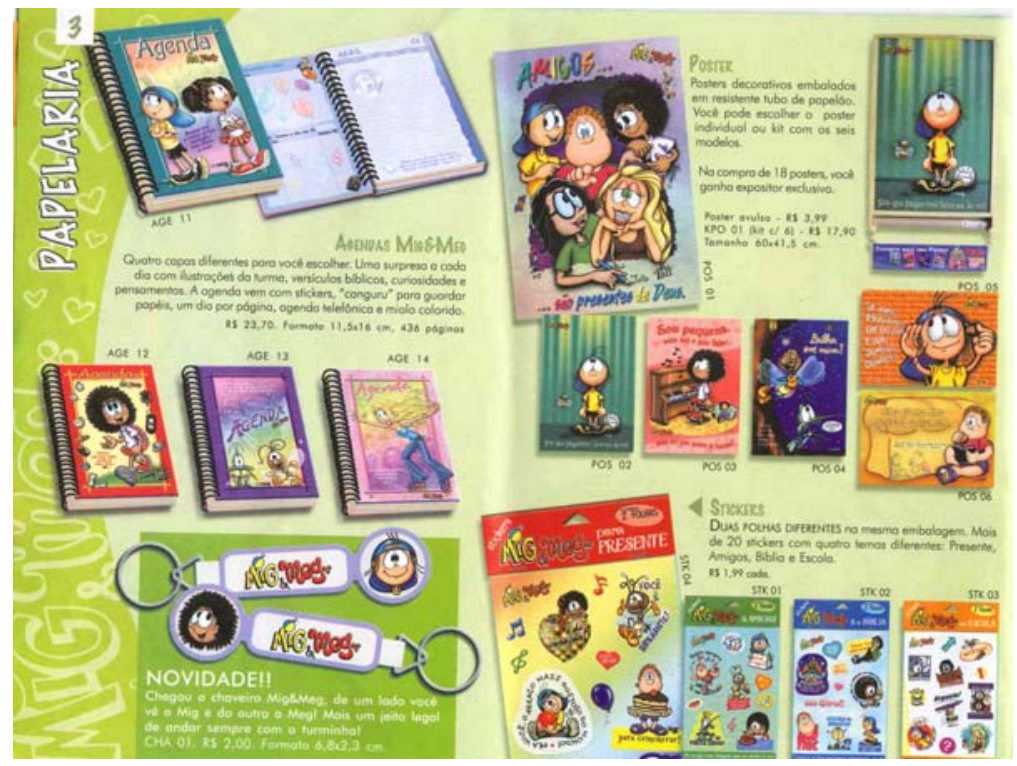

FIGURA 4) Excerto do Catálogo 2005 da Turma Mig \& Meg, criada por Márcia D'Haese em 1997. Agendas, chaveiros, pôsteres, stickers 
(figuras autocolantes), além de camisetas, materiais escolares, livros e CDs com histórias estão entre os produtos oferecidos não somente pela Editora ARCO, mas também por outras companhias evangélicas que passaram a lançar seus personagens.

Fonte: Editora ARCO.

Nas últimas edições da Expo Cristã São Paulo que visitamos (2006 e 2008), coletamos materiais de produtos infantis predominantemente brasileiros, tais como:

A) "Crianças Diante do Trono", parte infantil do famoso ministério de louvor (música) Diante do Trono, da Igreja Batista da Lagoinha. Os produtos são estampados com os desenhos de uma turma de objetos - uma boneca de pano, um porta-lápis, uma bola, um mico-leão, entre outros. Eles aparecem em capas de Bíblia, marca-páginas e cartões passe-adiante, entre outros ${ }^{41}$.

B) Frutos da Criação - nove vegetais representam os frutos do Espírito Santo (segundo Gálatas 5: 22-23). Em bonecos de pelúcia, cartões, cartões passe-adiante, marca-páginas e livros para colorir, estão estampados "Melana" (melancia), representando o amor; "Abacaxito", a alegria; "Jabotica", a fé; "Cebolita", a paciência; "Tomatião" (domínio próprio); "Maçanzito", a bondade; "Batabela", a paz; "Laranjoalo", a fidelidade; e "Perakato", a mansidão ${ }^{42}$;

C) A companhia Verbo tem se especializado em jogos de tabuleiro ("As jornadas de Paulo", "Êxodo", "Arca da Aliança"); CD-Roms de games ("Exército de Deus", "Moisés na Corte do Faraó"), além de bonecos, jogos de cartas ("Triunfo", "Jonas e o peixe", Card de memória", "Palavra Batida- Salmos e Provérbios"), Dvds de Max Lucado, entre outros produtos ${ }^{43}$.

D) Bonecos também são a proposta da DPI Importação e Exportação, que apresentou na edição da Expo Cristã 2008 os bonecos "Heróis da Fé", que falam versículos e contam histórias, 
importados dos Estados Unidos - bonecos de Jesus, Ester, Moisés, Maria, Sansão, Davi, Golias, Pedro, Noé, entre outros ${ }^{44}$.

E) Importado dos Estados Unidos também são a coleção de DVDs "O sótão encantado", misturando humanos e animação, e a coleção de DVDs "Querubim", de computação gráfica, ambos produzidos pela The Dove Foundation;

F) A famosa cantora gospel Aline Barros lançou em 2008 seu CD "Aline Barros \& Cia 2". Assim como ela, outros artistas passaram a investir no público infanto-juvenil, como o ministério "Os Ovelhas" e Mara Maravilha, que lançou uma linha de produtos com a personagem Marinha Maravilha, em 2006.

G) A editora Bom Pastor também lançou sua linha de figurinhas adesivas, do personagem "Strimilik", em estilo muito semelhante às figurinhas do Smilinguido, publicadas no início dos anos $1980^{45}$.

Uma empresa que tentou alcançar o mercado brasileiro sem sucesso até hoje é a Big Idea, produtora dos personagens "VeggieTales" ("Os Vegetais"), que são o maior sucesso de vendas do mercado infantil americano desde meados dos anos 1990. Na edição de 2008 da ExpoCristã, a Big Idea não compareceu com seu estande, ao contrário de edições anteriores. Talvez um sinal de que a produção brasileira, iniciada com Nosso Amiguinho e Smilinguido, tenha incentivado uma grande concorrência nacional, não deixando espaço até o momento para produtos internacionais. Porém, vale ressaltar que no ramo editorial, a predominância de títulos comercializados e vendidos é de traduções norte-americanas.

Um aspecto curioso dessa produção é que, apesar de uma grande parte desse material não ser fundamentalista, notamos no Brasil uma circulação e uma apropriação intensa de valores fundamentalistas, tais como descritos pela historiadora Karen Armstrong $^{46}$. Na mídia evangélica infantil, há diversas representações da infância como um projeto de vida cristã em 
longo prazo, no qual a criança deve encarnar o exemplo para as crianças não-cristãs e para a sociedade como um todo.

Nesses materiais, o cristão é exortado a ser ativista, guerreiro, vencedor, corajoso, enquanto caminha contra a sociedade secular, como alguém que faz a diferença por onde for. Por essa lógica, os evangélicos brasileiros procuram estabelecer uma fronteira precisa entre "eles" e "o mundo", tal como fazem os fundamentalistas americanos segundo o historiador Martin E. Marty ${ }^{47}$. Ao mesmo tempo em que demarcam seu território, esses evangélicos lutam para ganhar o "outro lado" para Cristo. Assim, a mídia torna-se uma ferramenta de evangelização para crianças e adultos, assim como um meio de sociabilidade, no qual estilos de vida evangélicos são construídos por meio de alternativas de entretenimento e por meio do uso diário de objetos como DVD, livros, vestuário, marca-páginas, adesivos de carro, material de escritório, presentes, bijuterias - e histórias em quadrinhos!

Quem poderia imaginar que os nocivos quadrinhos se tornariam diversão sadia? Obviamente, não nos referimos às revistas da Marvel ou de Will Eisner, mas ao Gibi do Smilinguido, conforme a carta de Arlete (23 anos, Araras-SP), que escreveu para o editor da revista:

(...) Que a cada dia Deus possa capacitar vocês, pois eu vejo a turma do Smilingüido como o melhor desenho, e em quadrinhos a melhor opção para a criança, pois hoje (não) em dia a televisão não oferece nada de bom para as crianças ${ }^{48}$.

\section{Conclusão}

Demonstramos como os produtos de mídia funcionam como formadores de sentido, e como eles ajudam a construir a religiosidade de seus consumidores. Entendemos a mídia nessa pesquisa como um processo de mão-dupla, e não como uma comunicação unidirecional. As audiências sempre assimilam o que desejam, precisam ou compreendem. No caso da cultura 
material, os usos de simples objetos de evangelização podem assumir diversos sentidos para seus consumidos. Como o comunicólogo americano Stewart Hoover destacou, a mídia é crucial para o processo de religiosidade autônoma, em que os indivíduos, afiliados ou não a religiões institucionais, escolhem e combinam suas crenças e práticas ${ }^{49}$.

Nossa análise da cultura material de massa foi influenciada pela obra de Colleen McDannell, que estudou o contexto americano no mercado cristão de varejo. $O$ modelo mercadológico evangélico que tem se constituído no Brasil inspirou-se no modelo americano, não somente pela profissionalização de seus setores, como também pelos seus produtos.

A maior contribuição de McDannell para nossa pesquisa foi a análise do "kitsch", isto é, objetos aparentemente descartáveis, tais como lembranças, bijuterias, decoração doméstica, vestuário, todos com mensagens cristãs. Tanto no trabalho de McDannell como no trabalho de David Morgan, o espaço-tempo do cotidiano é considerado fundamental para entender como a cultura evangélica é recriada e reafirmada pelo uso de objetos visíveis e materiais, que funcionam como veículos para a compreensão do invisível e para a união de pessoas. Por meio de seus usos diversos, os objetos cotidianos e/ou domésticos servem para comunicar a identidade religiosa do consumidor, e lembrá-lo sobre suas crenças numa situação de dilema ou descrença.

A mídia evangélica permite diferentes expressões culturais. Nós exploramos os diversos usos dos produtos de Smillinguido, especialmente por adolescentes e jovens mulheres. Após o fenômeno Smilinguido, o mercado evangélico se profissionalizou similarmente ao nível do mercado americano. Os produtos brasileiros dividem espaços nas prateleiras com produtos estrangeiros, a maioria deles importados da cultural fundamentalista e evangélica americana.

Desde os anos 1950 no Brasil, a mídia evangélica tem dado espaço para diferentes expressões denominacionais, ao mesmo tempo em que, paradoxalmente, tem padronizado temas, 
linguagens e formatos, almejando questões do dia-a-dia, para tornar a religiosidade algo pragmático e relevante para crentes e não-crentes, num contexto de competição e de secularização. Essa mídia é dinâmica e incorpora elementos internacionais, enquanto busca a aprovação da audiência local.

Assim, escrevemos uma história cultural da mídia evangélica infantil que reuniu comunicadores, audiências e suas mediações, conforme a abordagem cultural sugerida por Douglas Kellner. A inserção de muitos evangélicos nesse mundo de consumo de bens cristãos permitiu três fenômenos: a diluição de muitas barreiras denominacionais que separavam diversas igrejas, a recriação diária da tradição religiosa por meio da apropriação de cultura material e visual, e a ressignificação dos limites que separam a religião do mercado, para acomodar os novos interesses de empresários e consumidores que usam os mais variados objetos para "glorificar a Deus" nas inúmeras tarefas do dia-a-dia.

\section{Agradecimentos}

Expressamos nossa profunda gratidão a Márcia e Hialmar D'Haese, à Editora Luz \& Vida, ao Centro de Memória Ellen G. White, em Engenheiro Coelho-SP, pelos materiais e pelas entrevistas concedidas para a nossa pesquisa. Nosso profundo agradecimento para a Profa. Dra. Eliane Moura da Silva (Departamento de História-IFCH/Unicamp) pela paciente e diligente orientação desta pesquisa.

BELLOTTI, Karina Kosicki. "Theirs is the Kingdom of God": Evangelical Children's Media and the Religious Cultural Supermarket in Brazil (1950s to 2000s). História, v.28, n.1, p.621652, 2009.

Abstract: We present a Cultural History of the evangelical children's media produced in Brazil from the 1950s to the 2000s. 
We defend that the use of the media was an important factor in the constitution of a Brazilian evangelical culture directed toward individual consumerism and everyday life issues. The media directed toward children fomented an intense circulation of evangelical cultural products, allowing the creation of a transdenominational religiosity. We analyzed several products of the Brazilian evangelical media, such as the Adventist magazine "Nosso Amiguinho" (Our Little Friend), published since 1953, and the Brazilian Christian cartoon character, Smilinguido, a bestseller since the 1980s. We have focused on the acceptance of Smilinguido's products to identify the uses and the meanings of its material and visual cultural effects on the everyday lives of children and young women of different denominations in Brazil. With its success, an enormous market of Christian goods has opened in Brazil in the 1990s and the 2000s.

Keywords: Cultural History; Media and Religion; Cultural Supermarket.

\section{NOTAS}

${ }^{1}$ A distinção doutrinária básica entre protestantes e pentecostais seria a seguinte: enquanto os pentecostais dão ênfase ao batismo e aos dons do Espírito Santo, os protestantes não-pentecostais não enfatizam esses aspectos doutrinários e ritualísticos. Atualmente, a presença de movimentos avivados e pentecostais dentro de toda a cultura evangélica é a tendência predominante (cerca de $75 \%$ dos $17 \%$ da população brasileira que se declara evangélica, no censo do IBGE de 2000). Outras igrejas cristãs, como a Igreja Adventista do Sétimo Dia (IASD), a Igreja de Jesus Cristo dos Santos dos Últimos Dias e Testemunhas de Jeová, têm origem americana e são milenaristas, isto é, acreditam que o fim do mundo está próximo. Não adotaremos as classificações previamente utilizadas em estudos sociológicos (Cf. MARIANO, R. Neopentecostais: sociologia do novo pentecostalismo no Brasil. São Paulo: Loyola, 1997; FRESTON, P. Protestantes e política no Brasil: da Constituinte ao Impeachment. Tese de doutoramento em Sociologia. Campinas: IFCH/UNICAMP, 1993; MENDONÇA, A. G. \& VELASOUES FILHO, P. Introdução ao protestantismo. São Paulo: Edições Loyola,1990). 
Defendemos que as diferenças culturais constituem-se relacionalmente (Cf. HALL, S. A Questão da Identidade Cultural. Tradução de Andréa Borghi Moreira Jacinto e Simone Miziara Frangella, revisão técnica de Antonio Augusto Arantes, coleção Textos Didáticos-IFCH/UNICAMP, $n^{\circ}$. 18- junho de 2003, $3^{a}$ edição revista.). Com a pentecostalização do campo evangélico brasileiro, diferenças denominacionais não explicam completamente as distinções e as semelhanças entre evangélicos.

${ }^{2}$ MATHEWS, G. Cultura global e Identidade individual. Bauru: EDUSC, 2002.

3 HALL, S. A centralidade da cultura: notas sobre as revoluções culturais do nosso tempo. Educação \& Realidade, Porto Alegre, vol.22, $\mathrm{n}^{\circ}$. 2, julho/dezembro de 1997, pp. 15-46.

${ }^{4}$ HALL, S. Pensando a diáspora: reflexões sobre a terra no exterior. IN: SOVIK, Lia (org.). Op. Cit., p.44.

${ }^{5}$ KELLNER, D. A Cultura da Mídia. Bauru: EDUSC, 2000, pp. 52-53.

${ }^{6}$ MORGAN, D. Visual Piety - A History and Theory of Popular Religious Images. Los Angeles: University of California Press, 1998; Sacred Gaze - Religious Visual Cultural in Theory and Practice. Berkeley, Los Angeles, London: University of California Press, 2005.

${ }^{7}$ McDANNELL, C. Material Christianity, Religion and Popular Culture in America, Yale University Press, 1995.

${ }^{8}$ CAMPOS, L. S. Teatro, Templo e Mercado. Petrópolis, São Paulo, São Bernardo do Campo: Vozes/Simpósio Editora/Umesp, 1997.

${ }^{9}$ BELLOTTI, K.K. Uma Igreja Invisível? Protestantes históricos e meios de comunicação no Brasil (anos 50 a 80). Campinas-SP, 2000. Monografia de conclusão de graduação em História. Campinas: IFCH/Unicamp.

${ }^{10}$ A NCCCUSA foi um órgão interdenominacional que reuniu diversas igrejas protestantes americanas "mainline", isto é, igrejas que durante o século XIX e início do século XX foram hegemônicas no que se refere a movimentos missionários internacionais, influência política interna e arrecadação de fundos. Em sua maioria, eram igrejas presbiterianas, metodistas, congregacionalistas, episcopais e anglicanas. A sua influência decaiu ao longo dos anos 1950 e 1960, com o envolvimento de parte de seus membros em movimentos de defesa de direitos civis, o que provocou cisões e retiradas de financiamentos pela parte contrária a esses movimentos. Ao mesmo tempo, o movimento fundamentalista e evangelical ganhou força nos Estados Unidos, aglutinando forças religiosas protestantes conservadoras. No período em que o CAVE funcionou no Brasil, a NCCCUSA passou por essa 
transição, o que dificultou o envio de fundos para atividades mais custosas, como a compra de emissoras de rádio (Cf. BELLOTTI, K.K. "Delas é o Reino dos Céus": Mídia evangélica infantil na cultura pósmoderna do Brasil (1950-2000). Campinas-SP, 2007. Tese de doutoramento em História Cultural. Campinas: IFCH/Unicamp).

${ }^{11}$ CHESNUT, R. Competitive Spirits: Latin America's New Religious Economy. Oxford University Press, 2003; MARIANO, R. Análise sociológica do crescimento pentecostal no Brasil. São Paulo, 2001. Tese de doutorado em Sociologia - FFLCH/USP.

${ }^{12}$ O PURITANO. Rio de Janeiro, $\mathrm{n}^{\circ}$. 1690, ano 39, 10 de maio de 1938, p.1.

13 RABELLO, R. O Senhor te abençoe e.... São Paulo: SISAC, 2003. Formato: CD. Duração: 70 minutos.

${ }^{14}$ ROSA, J. O. O Evangelho Quadrangular no Brasil. Belo Horizonte: Betânia, 1978 (1976), 2a. ed.

${ }^{15}$ Essa tarefa também foi enfrentada por comunicadores evangélicos americanos na primeira metade do século XX, conforme encontrado em manuais de uso de recursos audiovisuais nas igrejas. Isso relativiza a idéia de que nos Estados Unidos o uso de mídia, apesar de mais antigo e comum entre diversas religiões, não tenha colocado problemas para sua membresia e sua liderança.

16 "Billions and billions of eyes and ears, gateways to the mind of man. This is century that has learned to appeal to them, thousands at one time. Sellers of soap, promoters of shows, propagators of the "isms" are putting up posters, getting out films, advertising on radio and television. And where is the Christian church? What is it doing? Some men have said that the world is won by that ideology whose exponents know best how to present it. If that is true, we Christians will have to catch up or give up. Christianity offers what all men seek - Abundant Life - yet it has won relatively few communicants. Perhaps the reason lies in the fact that we have not been successful in letting enough men see clearly enough what Christianity offers". (CHAIN, B. Livreto para a RAVEMCCO - divisão do Conselho Nacional de Igrejas de Cristo nos Estados Unidos, em 1959, s.n. - trecho enviado por cortesia de Sra. Beverly Chain, enviado por e-mail em 15 de julho de 2006 para a pesquisadora).

${ }^{17}$ CAMPOS, L.S. Op. Cit., pp. 205-238.

${ }^{18}$ HEELAS, P.(ed.) Religion, modernity and postmodernity. Blackwell Publishers, 1998.

${ }^{19}$ BELLOTTI, K. K., Op. Cit., 2007. 
20 ROSA, Z. de P. O Tico-Tico: meio século de ação recreativa e pedagógica. Bragança Paulista: EDUSF, 2002.

${ }^{21}$ SILVA Jr., G. A Guerra dos Gibis - a formação do mercado editorial brasileiro e a censura aos quadrinhos - 1933-1964. São Paulo: Companhia das Letras, 2004.

${ }^{22}$ Revista "Nosso Amiguinho". Santo André: CPB, agosto de 1966, p. 2.

${ }^{23}$ Revista "Nosso Amiguinho". Santo André: CPB, abril de 1967, p.2.

${ }^{24}$ Revista "Nosso Amiguinho". Santo André: CPB, agosto de 1966, p.18.

25 LEMOS, C. T. Ensino Religioso nas Principais Tendências Pedagógicas. In: SILVA, V. (org.). Ensino Religioso - educação centrada na vida; subsídio para formação de professores. São Paulo: Paulus, 2004, pp. 116-137.

${ }_{26}$ O roteirista Grzybowski (Catito) saiu do time de criação do Smilingüido em 1986, tornando-se um psicólogo cristão. Ele discordou das modificações aplicadas ao personagem, quando ele deixou de ser adulto para se tornar criança, a fim de se adequar ao formato de um desenho animado. Desde então Márcia D'Haese tornou-se a maior responsável pelo personagem, até o rompimento com a Editora Luz \& Vida em 1997.

27 MORGAN, D. Visual Piety - A History and Theory of Popular Religious Images. Los Angeles: University of California Press, 1998.

${ }^{28}$ Cf. mais informações sobre o personagem e seus produtos no website oficial: http://www.smilinguido.com.br/. Consultado em 15 de setembro de 2008.

29 "To worship while performing a mundane activity - skateboarding, scrubbing the tub, taking out the garbage - is laughable. For an Evangelical, however, God's presence can be felt in any situation. If you are outside of such a belief system, the mundane seems to impoverish faith; if you are within the system, faith glorifies the mundane" (McDANNELL, C. op.cit., p. 50).

30 "Textuality is about message-sending and about the correct decoding of the message. Accuracy, credibility, and authority are among the cultural preoccupations of textuality" (MORGAN, D. Op.cit, 2005, p.89).

${ }^{31}$ Agradecemos a Márcia D'Haese pelo acesso ao seu acervo.

${ }^{32}$ Protegemos a identidade dos remetentes, publicando somente as suas iniciais.

${ }^{33}$ Os nomes dos remetentes foram omitidos por nós.

34 Correspondência de S. e W, enviada em 2 de agosto de 1994 para Márcia D’Haese. Cf. BELLOTTI, K.K. Op. Cit., 2007, pp.259-260.

${ }^{35}$ McDANNELL, C. Op. Cit. 
${ }^{36}$ McDANNELL, C. Op. Cit., p. 272: "We can no longer accept that the 'appearance' of religion is inconsequential to the 'experience' of religion. The sensual elements of Christianity are not merely decorations that mask serious beliefs; it is through the visible world that the invisible world becomes known and felt".

37 CUNHA, M. N. "Vinho Novo em Odres Velhos": Um olhar comunicacional sobre a explosão gospel no cenário religioso evangélico no Brasil. São Paulo, 2004. Tese de doutoramento em Comunicação.

${ }^{38}$ Cf. website: < http://www.migmeg.com.br $>$. Consultado em 14 de setembro de 2008.

${ }^{39}$ Cf. website: <http://www.nossoamiguinho.com.br $>$, Consultado em 14 de setembro de 2008.

${ }^{40}$ Esse episódio problemático foi relatado em minha tese com maiores detalhes, por isso escolhemos não reproduzi-lo neste artigo. Contudo, vale ressaltar que Márcia D'Haese doou seus direitos autorais sobre Smilinguido após um longo conflito de interesses com a Editora Luz e Vida, que detém os direitos autorais desde 1997. D'Haese fundou uma nova editora, ARCO (Artes e Comunicações Cristãs), criando novos personagens, a turma de Mig \& Meg (Cf. BELLOTTI, K.K. Op. Cit., 2007, pp. 145-231).

${ }^{41}$ Cf. website: <http://www.criancasdt.com > Consultado em 15 de setembro de 2008.

${ }^{42}$ Cf. website: <http://www.frutosdacriacao.com > Consultado em 15 de setembro de 2008.

${ }^{43}$ Cf. website: <http://www.editoradarr.com.br > Consultado em 15 de setembro de 2008.

${ }^{44}$ Cf. website: <http://www.brinquedosheroisdafe.com.br $>$.

Consultado em 15 de setembro de 2008.

${ }^{45}$ Cf. website: $<$ http://www.bompastor.com.br $>$. Consultado em 15 de setembro de 2008.

${ }^{46}$ ARMSTRONG, K. Em nome de Deus: O fundamentalismo no judaísmo, no cristianismo e no islamismo. São Paulo: Companhia das Letras, 2001, pp.9-17.

${ }^{47}$ MARTY, M. E. and APPLEBY, R. S. (eds). Fundamentalists and Society - Reclaiming the Sciences, the Family, and Education. Chicago and London: The University of Chicago Press, 1993. (The Fundamentalist Project - vol.2).

${ }^{48}$ Smilingüido e sua turma em Quadrinhos, $n^{\circ}$. 38, novembro de 2006, p. 20. 
${ }^{49}$ HOOVER, S. Visual religion in media culture. In: MORGAN, D. \& PROMEY, S. (eds.). Visual Culture in American Religions. Los Angeles, University of California Press, 2001, pp. 146-159.

Artigo recebido em 01/2009. Aprovado em 03/2009 